\title{
A ACESSIBILIDADE NO DIREITO SOCIAL AO TRANSPORTE: CONCEITO NORMATIVO E SUA ESPECIFICAÇÃO CONCRETIZANTE.
}

\author{
Roberto Berttoni Cidade \\ Teófilo Marcelo de Arêa Leão Júnior
}

Resumo: O direito ao transporte, garantido constitucionalmente pela Emenda Constitucional n. 90, a cada dia necessidade de melhor objetivação. Com isso, neste trabalho, via pesquisa bibliográfica e método hipotético-dedutivo, busca-se identificar as características de fundamentalidade, contextualização histórica de contemporaneidade. Bem como, dá-se relevo ao instituto de acessibilidade como requisito essencial voltada a garantir "facilidades", "possibilidades" e "autonomia" ao cidadão com a renovação do paradigma histórico individualista para uma concretização coletivista de consumo dos direitos sociais de modo racional, sustentável e mais eficaz, garantindo adensamento à dignidade da pessoa humana, sem a pretensão de esgotamento da matéria.

Palavras-Chaves: 1. Acessibilidade; 2. Mobilidade; 3. Trânsito; 4. Qualidade de vida; 5. Transporte.

\section{INTRODUÇÃO}

Rotineiramente, em especial nos grandes centros urbanos, é reticente nos noticiários e demais mídias informativas das dificuldades de mobilidade urbana, gerado pela expansão desordenada das cidades, aliada ao fato histórico de valorização da utilização de transporte individual, causando grandes engarrafamentos, atrasos e impedimentos aos cidadãos de usufruir de grande parte de seus direitos fundamentais sociais, ou tem dificuldades de fazê-lo.

Em face desses problemas o legislador pátrio, com o uso do poder constituinte reformador, elegeu como direito fundamental o transporte. Em se tratando de norma-valor de caráter aberto, a sua concretização depende de especificação e conformação, que geralmente é dada pelos instrumentos infraconstitucionais. E, ao vasculhar os institutos contidos nestes instrumentos é encontrado, de modo reiterado, o elemento da acessibilidade, inclusive com definições normativas.

Ocorre que, para dar substância ao conceito de acessibilidade, o presente estudo se propõe a investigar, pela via de pesquisa bibliográfica e de utilização de método hipotéticodedutivo, dos componentes que o conformam sob os auspícios do direito fundamental social 
do transporte, cuja racionalidade teórica baseia-se nos fundamentos de conhecimento e legitimação normativa constitucional tradicionalmente invocados.

Assim, tende a contextualizar o cenário jurídico nacional acerca das possibilidades interpretativas do instituto da acessibilidade, bem como confrontá-lo em face dos diversos instrumentos em que ele figura, além de buscar nas práticas efetivas de sua incidência, nuanças de seu âmbito jurídico.

Tudo isso para dar conta das três dimensões necessárias de validade e legitimação do direito hoje exigidas, sendo de razão teórica formal, teórica material e prática, que podem ser resumidas em caráter científico, ideológico e sociológico.

\section{O DIREITO SOCIAL AO TRANSPORTE E SUA NATUREZA JURÍDICA}

À partir dos pressupostos metodológicos de conhecimento, validade e legitimidade jurídica hodierna dos direitos fundamentais (pós-positivista ou neopositivista), aqui compreendidos como aqueles recepcionados pela ordem constitucional, observa-se que o direito social ao transporte vigora como valor normativo de caráter estruturante, nos termos do entender de Joaquim José Gomes Canotilho (1993).

Isto porque a contemporaneidade reclama uma hermenêutica que utilize a reaproximação da ética ao direito, com o escopo de otimizar a Vontade da Constituição (HESSE, 1991), por meio de uma concretização plural e aberta (HÄBERLE, 2002) direcionada para a promoção das diversas dimensões de seus status (DIMOULIS, 2014), com fomento à garantia do valor maior, a dignidade da pessoa humana (BARROSO, 2005, p. 15), que tem como marco histórico na Declaração Universal dos Direitos Humanos de 1948, e hoje está abarcado como princípio jurídico no Artigo $1^{\text {o }}$, III da Constituição Federal de 1988, orientando tanto a produção como aplicação do direito pátrio.

Neste espectro, afere-se a fundamentalidade normativa do valor do direito social ao transporte pela valorização hierárquica dentro do sistema jurídico (fundamentalidade formal), também pela legitimação sócio-política de seu conteúdo, segundo as condições materiais de concretização (fundamentalidade material), conformando externamente seu âmbito de aplicabilidade irradiante à moda do pensamento de Robert Alexy, forte em Joaquim José Gomes Canotilho (1993, p.498) e Ingo Wolfgan Sarlet (2008. p. 25).

Ainda, imperioso destacar que foi em 2015, pela via do poder reformador, que o direito ao transporte foi inserido expressamente no rol dos direitos fundamentais, passando a constar no caput do art. $6^{\circ}$ da Constituição Federal ao lado do direito à educação, direito à 
saúde, direito ao trabalho, direito ao lazer, direito à segurança, direito à previdência social, direito à proteção à maternidade e à infância, direito à assistência aos desamparados (escolhas do legislador originário), direito à alimentação e direito à moradia. Sendo assim, o reconhecimento de fundamentalidade de qualquer direito tem por finalidade "conferir aos indivíduos uma posição jurídica de direito subjetivo, em sua maioria de natureza material, mas às vezes de natureza processual e, consequentemente, limitar a liberdade de atuação dos órgãos do Estado" (SARMENTO, 2010. p. 54).

Com este apanhado metodológico do conhecimento jurídico, realiza-se um corte temático quanto ao assunto deste tópico, limitando-se à investigação das característica e natureza jurídica do valor em comento, para objetivação e melhor aproveitamento do discurso, já que breve. Ademais, não se tem a pretensão de tratamento exaustivo, inclusive pela dinamicidade pratica e teórica pós-moderna que afeta o direito urbanístico, conceituado por Hely Lopes Meirelles de "conjunto de medidas estatais destinadas a organizar os espaços habitáveis, de modo a propiciar melhores condições de vida ao homem na comunidade" (MEIRELES, apud SILVA, 2010, p. 31). No mesmo sentido José Afonso da Silva:

[...] direito urbanístico (como de outro ramo jurídico qualquer): (a) o direito urbanístico objetivo, que consiste no conjunto de normas jurídicas reguladoras da atividade do Poder Público destinada a ordenar os espaços habitáveis - o que equivale dizer: conjunto de normas jurídicas reguladoras da atividade urbanística; (b) o direito urbanístico como ciência, que busca o conhecimento sistematizado daquelas normas e princípios reguladores da atividade urbanística. (SILVA, 2010, p. 37)

Desta forma, ao se analisar o instituto (CIDADE; LEÃO JUNIOR, 2016), constata-se que, mesmo antes do reconhecimento à categoria de direito fundamental, a conformação do direito ao transporte já preexistia em diversos instrumentos infraconstitucionais que até os dias atuais conferem concretização material, notadamente por meio do Estatuto das Cidades (Lei n. 10.257/01); Plano Nacional de Mobilidade Urbana (Lei 12.587/12); O Estatuto do Idoso e seu regulamento (Lei n. 10.741/03 e Decreto n. 5.934/06); Lei do Passe Livre e seu regulamento (Lei n. 8.899/94 e Decreto n. 3.691/00); Estatuto da Pessoa com Deficiência (Lei n. 13.146/15); Lei de prioridades de atendimento (Lei n. 10.048/00); Lei de Diretrizes e Bases da Educação (Lei 9394/96); Estatuto da Juventude e seu regulamento (Lei n. 12.852/13 e Decreto n. 8.537/15); Tratamento fora do domicílio (Lei Orgânica da Saúde no 8.080/90, disciplinada pela Portaria Federal n ${ }^{\circ}$ 055, de 24 de fevereiro de 1999 da Secretaria de Assistência à Saúde/Ministério da Saúde); e, Lei do Vale-Transporte (Lei n. 7.418/85). 
Quanto às suas característica, aponta a seguinte conclusão:

Nesta seara, ele [o direito ao transporte] foi sendo introduzido paulatinamente como direito meio para o acesso aos demais direitos sociais, via instrumentos normativos próprios como os que garantiram o Vale Transporte, o Passe Livre, gratuidades e descontos à pessoas em situações especiais como forma de equalizar as desigualdades sociais e agora formalmente em âmbito constitucional. (CIDADE; LEÃO JUNIOR, 2016, p. 213, grifo nosso)

De outra maneira, a materialidade em si do direito ao transporte se configura, de fato, como direito meio de acesso à inúmeros outros direitos sociais, pois demanda o deslocamento do indivíduo até as escolas, hospitais, moradias, praças e parques, local de trabalho, entre outros, pondo no centro da proteção as possibilidades materiais de sua eficácia, o que é aferido através da denominada mobilidade urbana, definida por Valter Fanini:

[...] atributo associado às pessoas e atores econômicos no meio urbano que, de diferentes formas, buscam atender e suprir suas necessidades de deslocamento para a realização das atividades cotidianas como: trabalho, educação, saúde, lazer, cultura etc. Para cumprir tal objetivo, os indivíduos podem empregar o seu esforço direto (deslocamento a pé), recorrer a meios de transporte não motorizados (bicicletas, carroças, cavalos) ou motorizados (coletivos e individuais) (2011, p. 10).

Tanto é assim, que o disposto no inciso II, do artigo $4^{\circ}$, da Lei 12.587/12 (Plano Nacional de Mobilidade Urbana) assevera:

Art. $4^{\circ}$ Para os fins desta Lei, considera-se:

[...]

II - mobilidade urbana: condição em que se realizam os deslocamentos de pessoas e cargas no espaço urbano;

Contudo, a mobilidade em si depende de outros fatores condicionantes, notadamente a acessibilidade, que o mesmo diploma legal supra (inciso III) especifica como "facilidade disponibilizada às pessoas que possibilite a todos autonomia nos deslocamentos desejados, respeitando-se a legislação em vigor;" assunto que que será pormenorizado no próximo item.

Ocorre que, a mobilidade (ou parte de seu conteúdo - acessibilidade) versa sobre direito social com historicidade progressiva e gradual voltada a promoção de igualdades de fato, possuindo grande carga do status positivus à luz da Teoria de Georg Jellinek (CANOTILHO, 1993, p. 171), podendo ser conceituada numa: 
[...] dimensão dos direitos fundamentais do homem, são prestações positivas proporcionadas pelo Estado direita ou indiretamente, enunciadas em normas constitucionais, que possibilitam melhores condições de vida aos mais fracos, direitos que tendem a realizar a regularização de situações sociais desiguais. (SILVA, 2005. p. 287)

Complementarmente, apenas relembra que hoje a doutrina tem por superada a distinção excludente das dimensões jurídicas dos direitos fundamentais, conforme dispõe Clèmerson Merlin Clève (2003, p. 156) e André Ramos Tavares (2012, p. 122), entre outros.

Isto é, os direitos fundamentais, por suas características históricas e conteúdo, são diferenciados em suas dimensões clássicas, a saber: (i) defesa: limitação ao poder público; (ii) prestacional: necessitam de atuação positiva do Estado; e (iii) injuntiva: reclama regulamentação de equiparação.

Porém, devem ser concretizados, ao menos em parcela mínima, com observância conjunta de todas as dimensões para a otimização de seus comandos, tanto nos conflitos verticais como horizontais. Em outras palavras, de maneira simplista, mesmo um direito qualquer de liberdade (de credo, por exemplo) que é predominantemente de limite (status negativus), também exige um comportamento positivo de instrumentalização do aparelho estatal (polícias e afins) a fim de combater fatos que impeçam o gozo dessa liberdade, seja em razão de particular ou do próprio Estado.

No mesmo sentido, um direito social (à educação, por exemplo), prestacional em sua essência (status positivus), exige um comportamento negativo (de não excluir possíveis fontes de conhecimento), seja por em razão de particular ou do próprio Estado.

Logo, com o direito fundamental ao transporte não poderia ser diferente, denotando uma natureza jurídica predominantemente prestacional (na esfera individual) e injuntiva (na esfera coletiva), reclamando políticas públicas que estabeleçam estratégias e programas governamentais à ordenar os recursos e coordenar as ações, públicas e privadas, a fim de atingir resultados socialmente relevantes e politicamente determinados. (BUCCI, 1997, p. 91), até por conta de seu caráter objetivo, pois:

[...] a constituição não é simples ideário. Não é apenas uma expressão de anseios, de aspirações e propósitos. É a transformação de um ideário, é a conversão de anseios e aspirações em regras impositivas, em comandos. Em preceitos obrigatórios para todos: órgãos do Poder e cidadãos" (MELLO, 2011. p. 11).

Neste contexto, assevera: 
A metodologia de análise das políticas baseia-se inicialmente em três atividades: a escolha das dimensões em torno das quais será feita a análise; a identificação dos agentes que intervêm no processo, seus interesses e recursos; e a seleção das variáveis que serão usadas para qualificar e quantificar as decisões e impactos da política. A identificação das dimensões, agentes e variáveis é seguida por um processo analítico de relacionamento entre eles, de acordo com combinações promissoras (VASCONCELLOS, 2001, p. 136).

Então, com subsídio nos ensinamentos de Maria Paula Dallari Bucci (2001), Carlos Eduardo de Freitas Fazoli e Diego Hermínio Stefanutto Falavinha (2010), Andréas J. Krell (2002), entre outros, tem-se que, para além da objetividade normativa dos direitos fundamentais, o aspecto subjetivo permite, ao menos em tese, a judicialização de conflitos se atestado a inexistência ou deficiência de políticas públicas, mediante provocação legítima do Poder Judiciário, para a pacificação social (CIDADE; LEÃO JUNIOR, 2016).

Com tudo isso encerra a análise do direito ao transporte (e sua natureza), firmando se tratar de verdadeiro valor normativo que compõe a Vontade da Constituição, estando presentes a fundamentalidade formal e material aberta e plural, que merece especificação e otimização a ser desenvolvido por meio de políticas pública, especialmente pelo seu caráter predominantemente prestacional (na esfera individual) e injuntivo (na esfera coletiva), o que autoriza, se necessário, sua judicialização.

\section{ACESSIBILIDADE: UM CONCEITO NORMATIVO.}

Inicialmente, cumpre destacar que o termo acessibilidade é, em geral, estudado enquanto garantia material de igualdade de indivíduos portadores de necessidades especiais para o usufruir dos direitos fundamentais em todas as suas modalidades. Ocorre que, embora esta ótica seja acertada, necessário frisar que se utiliza aqui maior amplitude à expressão, abrangendo, em termos teóricos, a perspectiva formal enquanto características ordinárias de qualquer instrumento legal (abstração e generalidade).

Sendo assim, ao se investigar o termo acessibilidade (ou suas variações semânticas de acesso aos direitos sociais), apura-se que ele aparece 13 (treze) vezes na Constituição Federal. Já, nas demais Leis supramencionadas, especificamente o termo acessibilidade, surge 84 (oitenta e quatro) vezes, e os termos afins como "acesso", "acessível", entre outros, figuram 146 (cento e quarenta e seis) vezes - (ora observados de modo global, incluindo acesso à informação, acesso à justiça, etc.). A redação se mostra em muitos casos repetitiva, inclusive no mesmo enunciado (artigo), o que induz a força protecionista que quer se imprimir aos direitos fundamentais. De outra forma, tornam evidente a preocupação legislativa em dar 
eficácia aos direitos sociais, na medida que a concretização depende materialmente da acessibilidade.

Desta feita, imperiosa a investigação do enquadramento fático à moldura legislativa, para melhor compreensão de seu âmbito. Aqui, parte-se do pressuposto da pessoalidade do gozo destes direitos, ou seja, por exemplo, para o indivíduo receber educação, deve ter acesso à escola; o direito à saúde, deve ter acesso ao hospital; e assim por diante. Tal acesso, portanto, implica nas possibilidades de ir e vir, o que desemboca necessariamente no direito ao transporte, evidenciando as bases do presente estudo, que se presta a uma tentativa de responder diversas questões como: O que é acessibilidade no transporte? A acessibilidade é um direito público subjetivo? A acessibilidade de uns implica em barreiras para outros? A quem compete definir os parâmetros de acessibilidade? Em se tratando de parcela de um direito fundamental, tem expressão horizontal? Em suma, busca-se, de modo singelo, atribuir métrica jurídica ao termo acessibilidade à luz do valor social do direito ao transporte.

Com isso, relembra que acessibilidade ao transporte está diretamente ligada ao direito urbanístico, como desenvolvido no item anterior, que encontra competência legislativa no artigo 21 da Constituição Federal, in verbis: "Compete à União: XX - instituir diretrizes para o desenvolvimento urbano, inclusive habitação, saneamento básico e transportes urbanos;", complementado pelos artigos $227, \S 2^{\circ}$ e 244 do mesmo diploma legal.

Então, não paira dúvidas que em se tratando de direito ao transporte (e sua acessibilidade) este deve ser regulamentado por Lei federal, o que não elide a possibilidade de delegação, nos termos no Parágrafo único do artigo 22 da Constituição Federal.

Assim, normativamente, há de se destacar que existem dois conceitos legais de acessibilidade, sendo eles:

Plano Nacional de Mobilidade Urbana (Lei 12.587/12) - Art. $4^{\circ}$ Para os fins desta Lei, considera-se: III - acessibilidade: facilidade disponibilizada às pessoas que possibilite a todos autonomia nos deslocamentos desejados, respeitando-se a legislação em vigor;

Estatuto da Pessoa com Deficiência (Lei n. 13.146/15); Art. $3^{\circ}$ Para fins de aplicação desta Lei, consideram-se: I - acessibilidade: possibilidade e condição de alcance para utilização, com segurança e autonomia, de espaços, mobiliários, equipamentos urbanos, edificações, transportes, informação e comunicação, inclusive seus sistemas e tecnologias, bem como de outros serviços e instalações abertos ao público, de uso público ou privados de uso coletivo, tanto na zona urbana como na rural, por pessoa com deficiência ou com mobilidade reduzida; 
Nesta seara, interessante ainda observar as disposições da ABNT 9050 de 2004 (Acessibilidade a edificações, mobiliário, espaços e equipamentos urbanos) que veio a substituir a ABNT 9050 de 1985:

3.1 acessibilidade: Possibilidade e condição de alcance, percepção e entendimento para a utilização com segurança e autonomia de edificações, espaço, mobiliário, equipamento urbano e elementos

Ainda, a ABNT 14022 de 2006 (Acessibilidade em veículos de características urbanas para o transporte coletivo de passageiros):

3.1 acessibilidade condição para utilização, com segurança e autonomia, total ou assistida, dos serviços de transporte coletivo de passageiros, por pessoa com deficiência ou mobilidade reduzida.

3.2 acessibilidade assistida condição para utilização, com segurança, do sistema de transporte coletivo de passageiros, mediante assistência de profissional capacitado para atender às pessoas com deficiência ou mobilidade reduzida.

Observa-se, portanto, todos estas definições, de modo geral, possuem como elemento comum a exigência de "facilidades", "possibilidades" e "autonomia", que dá a tônica do referido instituto.

A doutrina não discrepa, afirmando que “[...] acessibilidade pode ser compreendida como um conceito básico a ser pensado, avaliado e aplicado em todas as ações públicas que resultem em oferta de qualidade de vida, relacionados ao comportamento físico do espaço urbano" (BRASIL, 2006, p. 16), pois, a "acessibilidade refere-se ao número de oportunidades disponíveis a partir de determinada distância ou tempo de deslocamento" (HANSON; GIULIANO, 2004). Também, tida por "efetividade do sistema de transporte em conectar localidades separadas" (CARDOSO, 2008, p. 42); e, no mesmo sentido "a facilidade (ou dificuldade) com que os locais da cidade são atingidos pelas pessoas e mercadorias, medida pelo tempo e pelo custo envolvido" (VASCONCELOS, 1985, p. 26); em suma, “Acessibilidade constitui a facilidade, em distância, tempo e custo, em alcançar fisicamente os destinos desejados, encerrando a efetividade do sistema de transporte em conectar localidades separadas." (ARAÚJO et al, 2011, p. 574).

Por tudo isso, verifica-se pois, que acessibilidade trata do elemento nuclear da mobilidade urbana que, como expressão estruturante de direito fundamental (CANOTILHO, 1993) deve atender as dimensões essenciais da juridicidade, que se resumem nas (i) dimensão garantístico-defensiva, funcionado como defesa em face eventuais ingerências ou 
intervenções do Estado e demais poderes públicos; (ii) dimensão positivo-prestacional, na medida em que cumpre ao Estado e demais entidades públicas propiciar políticas públicas de realização; (iii) dimensão jurídica irradiante vinculando as atividades privadas e públicas do setor; (iiii) dimensão jurídico-participativa, demandando participação da sociedade civil.

Ainda, na visão de Romeu Kazumi Sassaki (1999), o conceito de acessibilidade comporta seis dimensões possíveis, a saber acessibilidade comunicacional; metodológica, instrumental; programática; atitudinal e arquitetônica, a superar as barreiras que dificultam ou impeçam o gozo dos direitos sociais. Mas superar quais barreiras? Na visão do autor supra mencionado, barreiras urbanísticas; nas edificações; nos transportes; na comunicação e informações. Dessa visão compartilha o Ministério das Cidades, que assim as especifica:

barreiras: qualquer entrave ou obstáculo que limite ou impeça o acesso, a liberdade de movimento, a circulação com segurança e a possibilidade de as pessoas se comunicarem ou terem acesso à informação, classificadas em:

a) barreiras urbanísticas: as existentes nas vias públicas e nos espaços de uso público;

b) barreiras nas edificações: as existentes no entorno e interior das edificações de uso público e coletivo e no entorno e nas áreas internas de uso comum nas edificações de uso privado multifamiliar;

c) barreiras nos transportes: as existentes nos serviços de transportes;

d) barreiras nas comunicações e informações: qualquer entrave ou obstáculo que dificulte ou impossibilite a expressão ou o recebimento de mensagens por intermédio dos dispositivos, meios ou sistemas de comunicação, sejam ou não de massa, bem como aqueles que dificultem ou impossibilitem o acesso à informação; (BRASIL, 2006, p. 54).

Para além das barreiras clássicas, Readymake, Polo Planejamento e Scipopulis (2018, p. 7), relacionam como principais problemas no deslocamento (em São Paulo), e portanto na acessibilidade segundo os termos acima referidos: Duração dos deslocamentos; Veículos individuais; Desigualdade na distribuição da rede; Congestionamento; Distância média percorrida com carro próprio; Custos e perda de produtividade; Sub-utilização dos veículos individuais; Poluição; Falta de acessibilidade; Acidentes; Custo dos acidentes em rodovias; Assédio; Qualidade do transporte público; Tarifa do transporte público; e, Segurança para ciclistas. Estas constatações são acompanhadas de dados numéricos obtidos em diversas fontes, cuja reprodução resta inviabilizada aqui, por razões claras.

De qualquer forma, confrontando as barreiras clássicas, com os principais problemas de mobilidade (que em última instância também se transformam em barreiras), apura-se notoriamente que as condições materiais que dificultam, ou até mesmo impossibilitam, o acesso ao direito ao transporte tem raízes históricas, seja na ausência de 
planejamento adequado para receber população que deixou a zona rural durante a industrialização nos anos 60 (sessenta), bem como escolha de prioridade às políticas que incentivavam o transporte rodoviário de caráter particular, na medida em que "os automóveis recebem até $90 \%$ dos subsídios dados ao transporte de passageiros no país, 12 vezes mais que o transporte público" (INSTITUTO DE PESQUISA ECONÔMICA APLICADA, 2011, p. 6).

No mesmo sentido:

[...] um modelo de desenvolvimento urbano excludente e altamente concentrador nos aspectos econômicos, territoriais e demográficos - cerca de $60 \%$ da população urbana brasileira vive hoje em 224 municípios com mais de 100 mil habitantes, dos quais 94 pertencem a aglomerados urbanos e regiões metropolitanas com mais de um milhão de habitantes -, privando as faixas de menor renda das condições básicas de inserção efetiva à cidade e ao meio urbano. (FANINI, 2011, p.10)

Com teor símile:

A partir do paradigma do individual, a rápida motorização no país ocorreria posteriormente à década de 1960 entre acordos e responsabilidades realizados entre poderes públicos e a inciativa privada, que possibilitaram a flexibilidade no gerenciamento de ganhos, determinando a principal razão da opção pelas rodovias e incentivo do automóvel no Brasil. (MASCARENHAS; RIBEIRO FILHO, 2016, p. 36).

Também:

A utilização desenfreada do automóvel modificou a distribuição modal do transporte urbano, ocasionando a deterioração dos transportes públicos. A ampliação do sistema viário para a fluidez dos automóveis drenou a maior parte dos recursos destinados aos transportes urbanos em detrimento do transporte coletivo (ARAÚJO et al, 2011, p. 578).

Há de se acrescer à estes fatores a desigualdade econômica na constituição dos espaços urbanos que, por razões econômicas, em especial especulativa, acabam estabelecendo regiões de exclusão e marginalização para as periferias, justamente àqueles que têm menores condições materiais de locomoção, consequentemente, agravando ainda mais as barreias de acessibilidade.

De outra forma, "As cidades têm seu crescimento condicionado pela disponibilidade do transporte, acarretando modificações no uso do solo" (ARAÚJO et al, 2011, p. 578), isto porque as elas, tem sua expansão entremeados de espaços vazios, criados por uma urbanização corporativa pautada por especulação fundiária e imobiliária, extroversão e 
periferização da população, propiciando, o assentamento da dimensão da pobreza, em modelo específico denominado centro-periferia. A esse respeito:

A periferia da cidade, local de população de baixo status social, ratifica, em um momento posterior, este seu papel: é o locus de correntes migratória da zona rural e de pequenas cidades, bem como de grupos provenientes de antigas periferias da cidade, agora valorizadas e que, por isso mesmo, eliminam parte de seus moradores. É, em parte, através do processo que se expande o espaço urbano ao longo da periferia popular, sem amenidades. (CORRÊA, 1989, p. 73)

Em suma:

As desigualdades territoriais são imensas e impactam o acesso à mobilidade: as redes de média e alta capacidade não alcançam os territórios mais distantes, causando impacto à população que habita as zonas adjacentes, caracterizada por possuir menor renda e que, em sua maioria, usa o transporte coletivo todos os dias para ir trabalhar nas áreas do centro expandido que concentram a maior parte das atividades. A consequência dessa relação é o aumento das distâncias percorridas e consequentemente do tempo de deslocamento. (READYMAKE, POLO PLANEJAMENTO; SCIPOPULIS, 2018, p. 6).

Portanto, ao se analisar as barreias clássicas (e demais elementos ensejadores de desigualdades) estabelece uma relação direita entre as escolhas políticas que privilegiaram, historicamente, a individualidade e o capital em detrimento do coletivo e social. Neste cenário, atribuir fundamentalidade ao direito ao transporte, de modo a extrair do ideário afeto à dignidade da pessoa humana uma tentativa de concretização da igualdade material, importa em utilizar do direito como instrumento, produto e finalidade dos anseios político-sociais, ao passo que passam a funcionar como critérios e limites da atuação do Estado e sociedade.

Neste compasso, o conceito normativo de acessibilidade traduz uma forma de superação de tais barreiras e desigualdades, fomentadas por décadas a fio, com escopo de dar "facilidades", "possibilidades" e "autonomia" ao cidadão de gozo direto e pessoal dos demais direitos sociais, com significativa elevação de sua qualidade de vida, pela “[...] manifestação mais característica do direito de locomoção, direito de ir e vir e também de ficar (estacionar, parar), assegurado na Constituição Federal” (SILVA, 2010, p. 178).

\section{ACESSIBILIDADE E AlgumAS PROPOSTAS DE MELHORIAS DA POLÍTICA PÚBLICA DE TRANSPORTE.}


De tudo o que foi exposto até o presente momento denota uma valorização do direito ao transporte, com incremento da acessibilidade para a eliminação das barreiras e desigualdades sociais. Logo, o planejamento estratégico de desenvolvimento deve englobar:

[...] o aspecto estático, referente a infra-estrutura viária, que abrange as redes correspondentes as modalidades de transporte considerado e suas instalações; e o aspecto dinâmico, respeitante a estrutura operacional, que abrange o conjunto de meios e atividades estatais, exercidos em cada modalidade de transporte, necessários e suficientes ao uso adequado da infra-estrutura viária. Em suma, o aspecto estático refere-se rede viária; e o dinâmico, aos transportes. (SILVA, 2010, p. 178-179)

Isto porque:

[...] dentro do atual contexto econômico-social, isto é, de uma "globalização" cujos resultados são severos em relação aos segmentos menos abastados da sociedade - introduzindo novos elementos de desigualdade - o transporte público constitui um importante instrumento de justiça social, na medida em que pode conduzir de modo mais racional o crescimento das cidades e das aglomerações urbanas, ou seja, torna possível uma acessibilidade mais equitativa à cidade e às suas possibilidades de emprego, de cultura e de lazer. (COCCO; SILVEIRA, 2011, p. 555)

Ou seja, a densificação do direito ao transporte tem importância que extrapola as práticas governamentais e seus regulamentos, operando verdadeiras transformações culturais, por meio de concepção e execução da acessibilidade equitativa e democrática, portanto, o debate proposto não deve ficar restrito à técnicos jurídicos ou engenheiros de trafego, atendendo diretamente a sociedade como um todo.

Com isso, encontra-se em pauta a melhoria e barateamento do serviço de transporte público, com alinhamento aos princípios que regem a Administração Pública, insertos no artigo 37 da Constituição Federal, com relevância aqueles afetos à eficiência. Nesse sentido:

São considerados princípios que regem os serviços públicos os princípios da supremacia do interesse público, do dever inescusável do Estado de prestar o serviço, da universalidade ou generalidade, da permanência ou da continuidade, da eficiência ou mutabilidade, da modicidade das tarifas e da motivação. (PONTES; FARIA, 2012, p. 68).

Com efeito, a modicidade das tarifas cobradas por esse tipo de transporte se encontram abrangidas pela "atividade ordenadora da via pela Administração [que] ocorre num duplo sentido: na criação (ou autorização da criação) da rede viária necessária ao exercício da função e do direito de circulação e na regulamentação do uso da mesma. (SILVA, 2010, p. 180). 
Por outro turno, uma das principais formas utilizadas para o cumprimento dessa tarefa é a elaboração de cartilhas institucionais que se prestam, a um só tempo, tanto a informar acerca dos direitos do cidadão, quanto a educar para práticas mais eficazes e sustentáveis do uso do espaço urbano e os modais de mobilidade, pois "[...] um dos fatores decisivos na caracterização da acessibilidade ao ambiente é a possibilidade de os indivíduos perceberem e compreenderem o espaço, e as informações nele contidas" (BINS ELY; DISCHINGER; MATTOS, 2002). A título de exemplo, elenca:

BRASIL. Ministério das Cidades. Brasil Acessível. Programa brasileiro de acessibilidade urbana. Cadernos 2. Brasília, 2006;

Trânsito e mobilidade humana: Psicologia, Educação e Cidadania / org. por Clair Ana Mariuza e Lucio Fernando Garcia. - Porto Alegre: Ideograf/ Conselho Regional de Psicologia do Rio Grande do Sul, 2010;

BRASIL. Ministério das Cidades. Política Nacional de Mobilidade Urbana. Brasília, 2013.

Serviços essenciais: transporte coletivo. Núcleo Especializado de Defesa do Consumidor. São Paulo: Defensoria Pública, 2017

Conjuntamente à tais instrumentos, também com viés de informação e otimização da utilização da vias púbicas, o avanço tecnológico propicia, notadamente pelo uso de aplicativos dos smartphones como o MoveCidade (do IDEC), Google Maps, Waze, Moovit, CityMappper, para veículos; WalkScore para pedestres; RoadBike, BikeMap, Spotcycle, Strava, para ciclistas; onde, muitos deles são alimentados por portais de dados abertos que disponibilizam informações sobre o "transporte, ambientais, meteorológicos, estatísticos, financeiros, científicos, culturais e geoespaciais e teve como um dos objetivos permitir o reúso dos dados gerados pelas administrações públicas" (READYMAKE, POLO PLANEJAMENTO; SCIPOPULIS, 2018, p. 10). Enfim, as novas tecnologias impactam diretamente na forma de consumo dos bens públicos, especialmente garantindo o aspecto da autonomia, haja vista o serviço de localização global fornece aos seus usuários condições de melhor planejamento de uso de seu tempo de deslocamento.

Por fim, com fundamento na concepção criada por uma comissão em Washington (EUA) em 1963, um conceito de Desenho Universal, com significado de Desenho Livre de Barreiras, para atender à todos, inclusive os portadores de necessidades especiais, tende adaptar as áreas urbanas, aparelhos e equipamentos de acesso ao público, de modo a não necessitar de elementos especiais para a utilização dos mesmos (BRASIL, 2006). 
Portanto, o desenho universal trata da geração de ambientes, tecnologias, programas e serviços que dispensem adaptações, podendo assim, ser utilizados por todas as pessoas; sendo que os "produtos" gerados sejam de utilização equiparável, flexível, simples, tolerante ao erro, que informe de maneira eficaz suas formas de uso, que possuam tamanhos e espaços que viabilizem o uso e exijam pouco esforço físico (COSENZA; RESENDE, 2006, p. 31).

Ou seja, "Esta definição de público usuário como sendo TODOS inclui não apenas a universalidade numérica, mas, e principalmente, a enorme gama de variações do ser humano: altos, baixos, obesos, idosos, crianças, gestantes e, também, pessoas com deficiências diversas" (BRASIL, 2006, p. 24), que é assim normativamente fixado:

Desenho Universal é aquele que visa atender a maior gama de variações possíveis das características antropométricas e sensoriais da população. (ABNT NBR-9050:2004)

Desenho Universal é a concepção de espaços, artefatos e produtos que visam atender simultaneamente todas as pessoas, com diferentes características antropométricas e sensoriais, de forma autônoma, segura e confortável, constituindo-se nos elementos ou soluções que compõem a acessibilidade. (Decreto Federal. N ${ }^{\circ}$ 5.296/04, Art. $8^{\circ}$, Inciso IX)

Essa ideia de Desenho Universal, portanto, é regida pelos seguintes princípios: (i) Equiparação nas possibilidades de uso: possuindo design forma útil às pessoas com toda sorte de habilidades (capacidades); (ii) Flexibilidade no uso: para atender indistintamente os usuários acima elencados; (iii) Uso Simples e intuitivo: garante fácil compreensão, dispensando experiência, especificidade de formação, conhecimento de outros idiomas ou da capacidade de concentração; (iv) Informação perceptível: dá ao usuário condições de obtenção de informação sem levar em conta a necessidade de todas as capacidade sensorial ou de condições ambientais; (v) Tolerância ao erro: diminui eventual risco e consequiências indesejadas em razão de ações involuntárias ou imprevistas; (vi) Mínimo esforço físico: permite o efetivo uso mediante mínimo de esforço, de forma eficiente e confortável; (vii) Tamanho e espaço para o acesso e o uso: possibilita o uso independentemente da compleição física do usuário. (BRASIL, 2006).

A análise dessa práticas demonstram que houve uma severa alteração do modo de realização de políticas públicas no setor de transportes, principalmente pela conscientização da população da inadequação das vias em face da quantidade de pessoas que se deslocam diuturnamente, deixando para traz o paradigma individualista, sendo norteado a concretização 
desse direito fundamental pelo interesse social, ou seja, de caráter coletivo, numa tentativa de diminuir quantitativa e qualitativamente os conflitos viários.

\section{CONCLUSÃO}

Da pesquisa realizada tencionou-se em verificar o reconhecimento do direito ao transporte como direito fundamental, e consequentemente um valor de caráter aberto que necessita de especiação e concretização.

Nessa investigação, especialmente pela gama de instrumentos regulatórios da atividade de transporte, que impõe limites e norteiam o uso do espaço público, com o fito de possibilitar ao cidadão condições efetivas e materiais de usufruir dos demais direitos fundamentais sociais, aquele possui natureza jurídica de instrumento meio.

Acresce-se a este fato a sua valorização com a positivação explícita no rol dos direitos fundamentais sociais, denotando ser uma norma estruturante, contemplada com força vinculante tanto ao Estado como à sociedade, e, em razão disso, passível de, ao menos em tese, judicialização.

Nesta seara, realizou-se um novo corte temático, passando a observar especificamente o instituto da acessibilidade, por ser compreendido como parte e orientado pelo direito social ao transporte. Assim, procurou-se estabelecer parâmetros de especificação de seu âmbito de controle à partir de seu conceito normativo.

Para tanto, desbordou os limites léxicos de seu enunciado e foi buscar as razões jurídicas, ideológicas e históricas do instituto da acessibilidade estar incisiva e reiteradamente contido nas leis que regulamentam o direito social ao transporte.

Com isso, apurou que em seu cerne está a exigência em favor do cidadão de práticas que confiram "facilidades", "possibilidades" e "autonomia", não apenas para solucionar conflitos surgidos exclusivamente na contemporaneidade, mas também aqueles derivados de anos de deficiência de planejamento no processo de urbanização de nosso país. Em suma, a barreias que se pretende superar com este instituto, em última instância, são oriundas da ausência de uma consciência voltada ao interesse coletivo, vez que, historicamente, privilegiou-se a individualidade, tanto nos investimentos como nas práticas relativas ao transporte.

Desta feita, sente-se uma alteração da perspectiva institucional de concretização de política pública ao transporte, pela existência de algumas propostas renovadoras, que perpassam pelas práticas tarifárias, acesso à informação e educação do consumo consciente e 
sustentável dos meios de transporte, além da adoção do denominado Desenho Universal, todos voltados à uma postura coletivista, de menor impacto e maior efetividade, a fim de maximizar, não só o direito fundamental social ao transporte, que é de meio, mas todos os demais direitos fundamentais sociais.

\section{REFERÊNCIAS}

BARROSO, Luís Roberto. Curso de direito constitucional contemporâneo: os conceitos fundamentais e a construção do novo modelo. Rio de Janeiro: Saraiva, 2009.

BINS ELY, Vera Helena Moro; DISCHINGER, Marta; MATTOS, Melissa Laus. Sistemas de Informação ambiental: elementos indispensáveis para a acessibilidade e orientabilidade. Recife, 2002. In: VII CONGRESSO LATINO-AMERICANO DE ERGONOMIA, XII CONGRESSO BRASILEIRO DE ERGO-NOMIA, I SEMINÁRIO BRASILEIRO DE ACESSIBILIDADE INTEGRAL, Anais [...] Recife, 2002.

BRASIL. Ministério das Cidades. Brasil Acessível. Programa brasileiro de acessibilidade urbana. Cadernos 2. Brasília, 2006.

BUCCI, Maria P. D., Políticas públicas e direito administrativo. Revista de Informação Legislativa. Brasília, 1997, Pp. 89-98.

et al. Direitos humanos e políticas públicas. São Paulo, Pólis, 2001.

CANOTILHO, José Joaquim Gomes. Direito Constitucional. 6 edição revista. Coimbra: Libraria Almedina Coimbra, 1993.

CARDOSO, C. E. P. (2008). Análise do transporte coletivo urbano sob a ótica dos riscos e carências sociais. Tese de Doutorado, Programa de Pós-graduação em Serviço Social, Pontifícia Universidade Católica de São Paulo, São Paulo, SP.

CIDADE, Roberto Berttoni; LEÃO JUNIOR, T. M. A. O Direito ao Transporte como Direito Fundamental Social. Revista de Direito Urbanístico, Cidade e Alteridade. Brasília, v. 2, n. 1. p. 196-216, jan-jun. 2016.

CLÈVE, Clèmerson Merlin. A eficácia dos direitos fundamentais sociais. Crítica Jurídica, Curitiba, v. 22, p. 17-29, 2003.

COCCO, Rodrigo Giraldi; SILVEIRA, Márcio Rogério. Transporte Público Coletivo: Acessibilidade e Crise nas Cidades do Interior Paulista. In: SILVEIRA, Márcio Rogério (Org.). Circulação, transporte e logística de diferentes perspectivas. 1. ed. São Paulo: Outras Expressões, 2011.

CORRÊA, Roberto Lobato. O Espaço Urbano. São Paulo: Editora Ática, 1989. 
COSENZA, Izabela Fernandes; RESENDE, Ana Paula Crosara de. A cidade e as pessoas com deficiência: barreiras e caminhos. Revista Sociedade \& Natureza, v. 18, n. 35, Universidade Federal de Uberlândia. Uberlândia: 2006.

DIMOULIS, Dimitri; MARTINS, Leonardo. Teoria geral dos direitos fundamentais. $5^{\mathrm{a}}$ ed. São Paulo: Revista dos Tribunais, 2014.

FANINI, Valter. Mobilidade Urbana. Série de Cadernos Técnicos. Publicações temáticas da Agenda Parlamentar do Conselho Regional de Engenharia, Arquitetura e Agronomia do Paraná - CREA-PR. 2011. Disponível em:< http://www.creapr.org.br/index.php?option=com_phocadownload \& view $=$ category $\&$ download $=538: \operatorname{mobilidad}$ e-urbana\&id=37:cadernos-tecnicos.>. Acesso em: 08 out. 2015.

FAZOLI, Carlos Eduardo de Freitas; FALAVINHA, Diego Hermínio Stefanutto. Interpretação e fundamentação nas decisões judiciais sobre políticas públicas. Revista Estudos Jurídicos. Franca-SP: Unesp, a. 14, n.1, p. 179-198, 2010.

HÄBERLE, Peter. Hermenêutica Constitucional. A Sociedade aberta dos interpretes da Constituição: Contribuição para a interpretação pluralista e "procedimental" da Constituição. Tradução: Gilmar Ferreira Mendes. Porto Alegre-RS: Sergio Antônio Fabris Editor, 2002.

HANSON. S.; GIULIANO. G. The Geography of Urban Transportation. The Guilford Press. 3rd Edition. New York, 2004.

HESSE, Konrad. A força normativa da constituição. Trad. Gilmar Ferreira Mendes. Porto Alegre-RS: Sergio Antônio Fabris Editor, 1991.

INSTITUTO DE PESQUISA ECONÔMICA APLICADA. Comunicado do IPEA n. 94: Mobilidade urbana no Brasil: Brasília, 2011.

KRELL, Andréas J. Direitos sociais e controle social no Brasil e na Alemanha. Porto Alegre: Sérgio Antônio Fabris Editor, 2002.

MASCARENHAS, R. R.; RIBEIRO FILHO, V. Mobilidade urbana nos países em desenvolvimento: uma analogia do transporte público urbano a partir da opção rodoviária e do automóvel no Brasil. OBSERVATORIUM: Revista Eletrônica de Geografia. Uberândia: Universidade Federal de Uberlândia, v.7, n.20, p. 30-44, nov/2016.

MELLO, Celso Antônio Bandeira de. Eficácia das normas constitucionais e direitos sociais. 1 ed., $3^{\text {a }}$ tiragem. São Paulo; Malheiros Editores, 2011.

ARAÚJO, M. R. M.; OLIVEIRA, J.M.; JESUS, M. S.; SÁ, N.R.; SANTOS, P. A. C. ; LIMA, T. C. . Transporte público coletivo: discutindo acessibilidade, mobilidade e qualidade de vida. Psicologia e Sociedade (Impresso), v. 23, p. 574-582, 2011.

PONTES, Daniele Regina; FARIA, José Ricardo Vargas de. Direito municipal e urbanístico. ed. rev. Curitiba, PR: IESDE, 2012. 
READYMAKE; POLO PLANEJAMENTO; SCIPOPULIS. O impacto da inovação tecnológica na mobilidade urbana da cidade de São Paulo. São Paulo: ForumMobi; Instituto Ethos; Instituto Friedrich Naumann, 2018.

SARLET, Ingo Wolfgang. Os Direitos Sociais como Direitos Fundamentais: contributo para um balanço aos vinte anos da Constituição Federal de 1988. Revista do Instituto de Hermenêutica Jurídica, $2008 . \quad$ Disponível em: $<$ http://www.stf.jus.br/portal/cms/verTexto.asp?servico=processoAudienciaPublicaSaude \&pagina=Artigos $>$ Acesso em 12 out.2015

SARMENTO, Daniel. Por Um Constitucionalismo Inclusivo: História Constitucional Brasileira. Teoria da Constituição e Direitos Fundamentais - Rio de Janeiro: Lumen Juris, 2010.

SASSAKI, Romeu Kazumi, Inclusão: construindo uma sociedade para todos. $3^{\text {a }}$ edição. Rio de Janeiro: Editora WVA, 1999.

SILVA, José Afonso da. Curso de Direito Constitucional Positivo. 25 ed. São Paulo: Malheiros Editores, 2005.

Direto urbanístico brasileiro. 6 ed. rev. atual. São Paulo: Malheiros, 2010.

TAVARES, André Ramos. Curso de direito constitucional. $10^{\circ}$ ed. São Paulo: Saraiva, 2012.

VASCONCELLOS, Eduardo Alcântara. Transporte urbano, espaço e eqüidade: análise das políticas públicas. 2. Ed.São Paulo: Annablume, 2001.

O que é o trânsito. São Paulo: Brasiliense, 1985. 